\title{
SI: Energy Renormalization for Coarse-Graining a Biomimetic Copolymer, Poly(catechol-styrene)
}

\author{
Martha Dunbar ${ }^{\dagger}$ and Sinan Keten $*,+, \dagger$ \\ $\dagger$ Department of Mechanical Engineering, Northwestern University, Evanston, Illinois \\ 60208, USA \\ $\ddagger$ Department of Civil \& Environmental Engineering, Northwestern University, Evanston, \\ Illinois 60208, USA \\ E-mail: s-keten@northwestern.edu
}

Phone: 847-491-5282 


\section{Bonded Term Optimization}
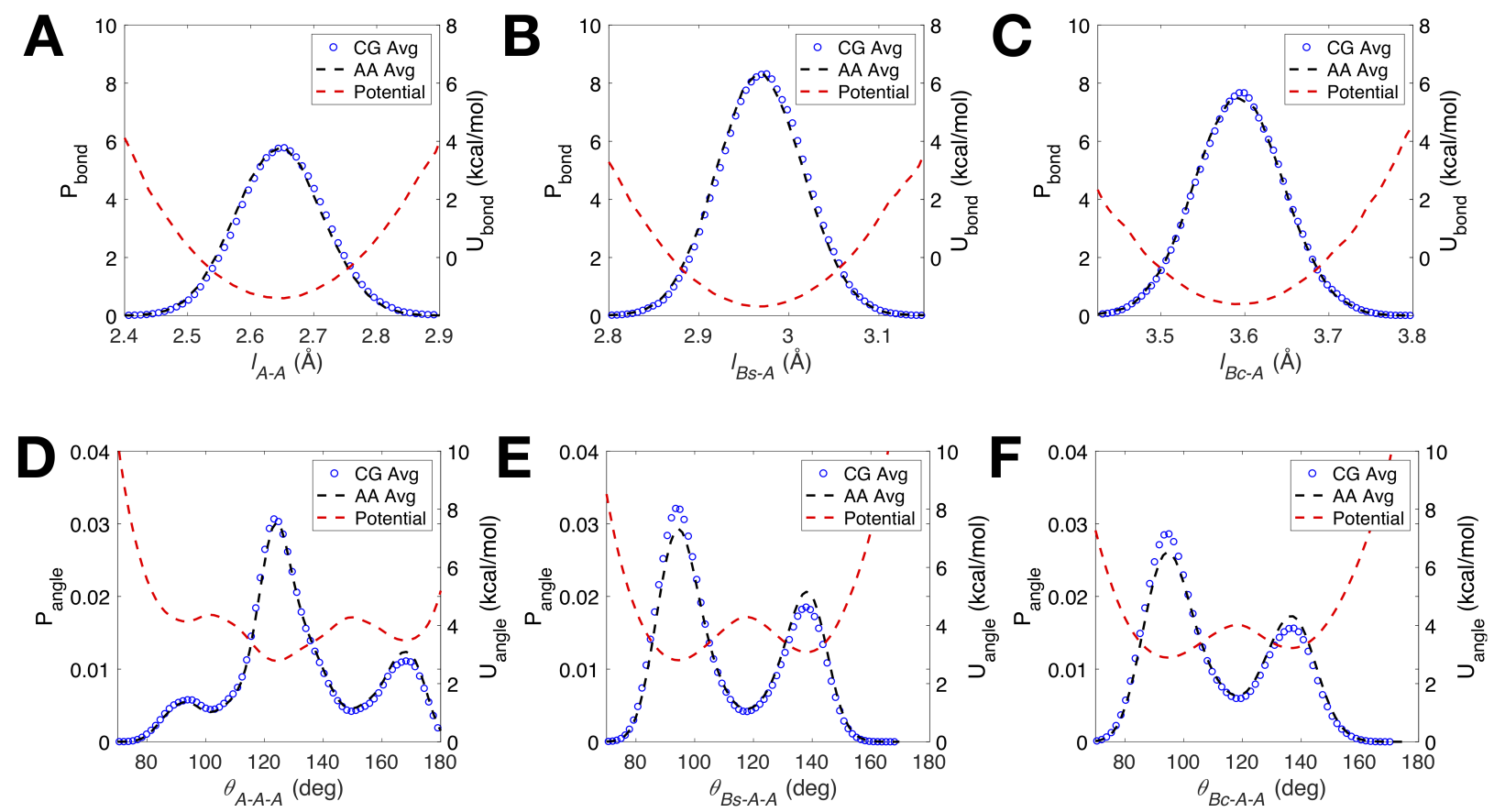

Figure S 1: Distributions for poly(catechol-styrene) $A-A$ bonded terms (A), $A$ - $B_{s}$ bonded terms (B), $A-B_{c}$ bonded terms (C), $A-A-A$ angle terms (D), $B_{s}-A-A$ angle terms (E), $B_{c}-A-A$ angle terms $(\mathrm{F})$.
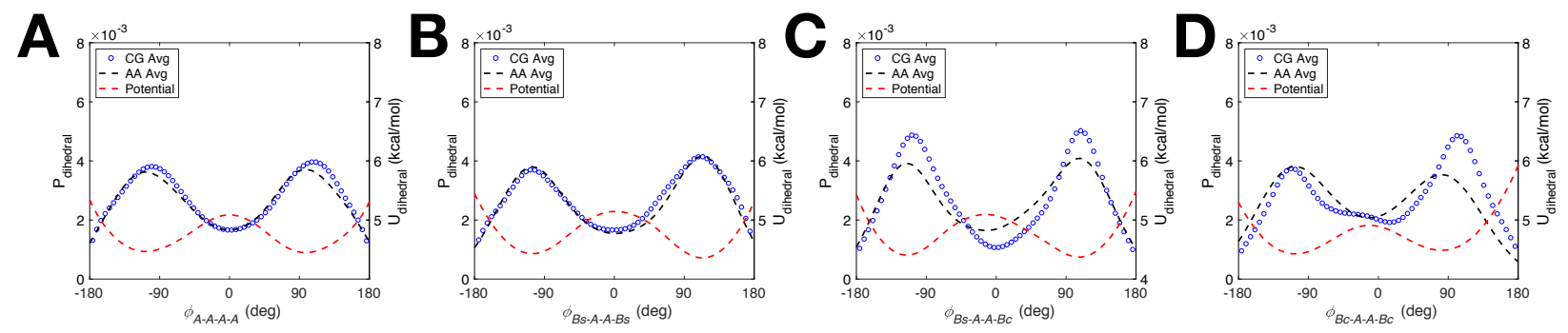

Figure S 2: Distributions for poly(catechol-styrene) (A) $A-A-A-A$ dihedral (B), $B_{s}-A-A-B_{s}$ dihedral (C), $B_{s}-A-A-B_{c}$ dihedral and (D), $B_{c}-A-A-B_{c}$ dihedral.

\section{Non-Bonded Term Optimization}

The energy renormalization factors are given by

$$
\alpha(T)=\frac{\left(\alpha_{A}-\alpha_{G}\right)}{1+\exp \left(-k\left(T-T_{T}\right)\right)}+\alpha_{G}
$$


where $\alpha_{G}$ and $\alpha_{A}$ are the $\alpha$ in the glassy and Arrhenius regime respectively, $T_{T}$ is crossover point of the sigmoidal function, and $k$ controls the width of the transition region and $\beta(T)=$ $a T+b$, where $a$ and $b$ are fitting constants. Together these are used to renormalize the LJ non-bonded parameters as a function of temperatures, in the form $\sigma_{j j}(T)=\beta(T) \sigma_{j j}^{0}$ and $\epsilon_{j j}(T)=\alpha(T) \epsilon_{j j}^{0}$.

Table 1: $\sigma_{j j}^{0}$ for Varying Catechol to Styrene Ratios

\begin{tabular}{|c|c|c|c|}
\hline Ratio & $\mathrm{AA}$ & $\mathrm{B}_{\mathrm{s}} \mathrm{B}_{\mathrm{s}}$ & $\mathrm{B}_{\mathrm{c}} \mathrm{B}_{\mathrm{c}}$ \\
\hline $0: 1 \mathrm{C}: \mathrm{S}$ & 4.62 & 5.08 & - \\
\hline $1: 5 \mathrm{C}: \mathrm{S}$ & 4.62 & 5.08 & 5.34 \\
\hline $1: 2 \mathrm{C}: \mathrm{S}$ & 4.62 & 5.08 & 5.25 \\
\hline $1: 1 \mathrm{C}: \mathrm{S}$ & 4.62 & 5.08 & 5.38 \\
\hline
\end{tabular}

Table 2: $\epsilon_{j j}^{0}$ for Varying Catechol to Styrene Ratios

\begin{tabular}{|c|c|c|c|}
\hline Ratio & AA & $\mathrm{B}_{\mathrm{s}} \mathrm{B}_{\mathrm{s}}$ & $\mathrm{B}_{\mathrm{c}} \mathrm{B}_{\mathrm{c}}$ \\
\hline $0: 1 \mathrm{C}: \mathrm{S}$ & 0.265 & 0.339 & - \\
\hline $1: 5 \mathrm{C}: \mathrm{S}$ & 0.265 & 0.339 & 0.513 \\
\hline $1: 2 \mathrm{C}: \mathrm{S}$ & 0.265 & 0.339 & 0.437 \\
\hline $1: 1 \mathrm{C}: \mathrm{S}$ & 0.265 & 0.339 & 0.368 \\
\hline
\end{tabular}

Table 3: $\beta(T)$ Fitting Parameters for Varying Catechol to Styrene Ratios

\begin{tabular}{|c|c|c|}
\hline Ratio & a & b \\
\hline $0: 1 \mathrm{C}: \mathrm{S}$ & $1.050 \mathrm{E}-4$ & 1.046 \\
\hline $1: 5 \mathrm{C}: \mathrm{S}$ & $8.958 \mathrm{E}-5$ & 1.045 \\
\hline $1: 2 \mathrm{C}: \mathrm{S}$ & $8.658 \mathrm{E}-5$ & 1.046 \\
\hline $1: 1 \mathrm{C}: \mathrm{S}$ & $8.012 \mathrm{E}-5$ & 1.031 \\
\hline
\end{tabular}


Table 4: $\alpha(T)$ Fitting Parameters for Varying Catechol to Styrene Ratios

\begin{tabular}{|c|c|c|c|c|}
\hline Ratio & $\alpha_{A}$ & $\alpha_{G}$ & $T_{T}(\mathrm{~K})$ & $k\left(\mathrm{~K}^{-1}\right)$ \\
\hline $0: 1 \mathrm{C}: \mathrm{S}$ & 1.515 & 2.643 & 613.2 & 0.0135 \\
\hline $1: 5 \mathrm{C}: \mathrm{S}$ & 1.608 & 2.768 & 635.8 & 0.0161 \\
\hline $1: 2 \mathrm{C}: \mathrm{S}$ & 1.766 & 3.188 & 636.8 & 0.0136 \\
\hline $1: 1 \mathrm{C}: \mathrm{S}$ & 2.168 & 3.802 & 628.6 & 0.0151 \\
\hline
\end{tabular}
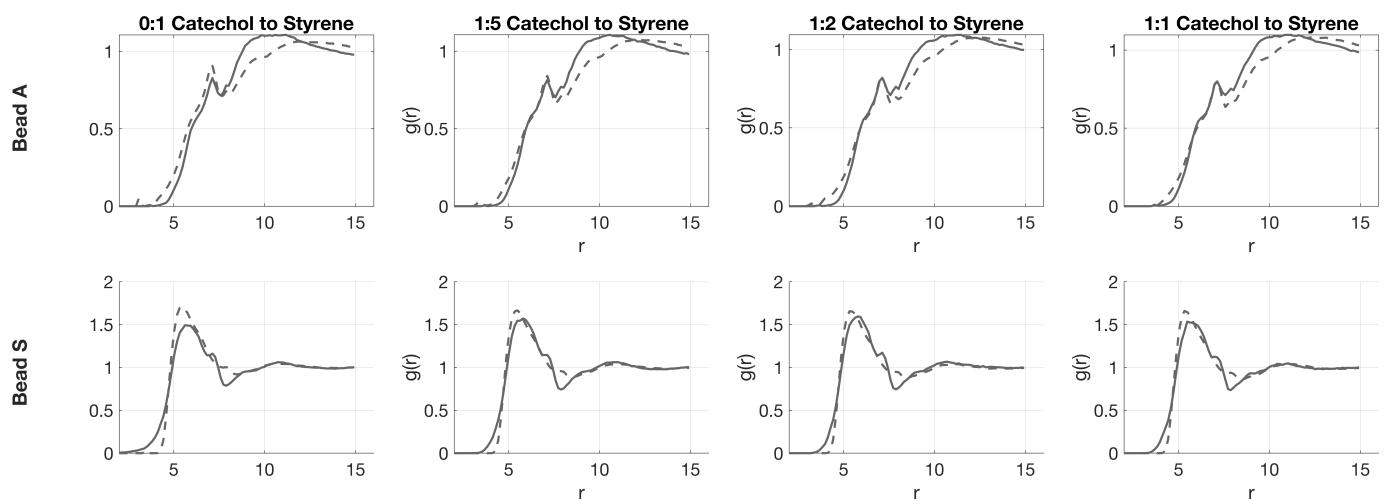

@i
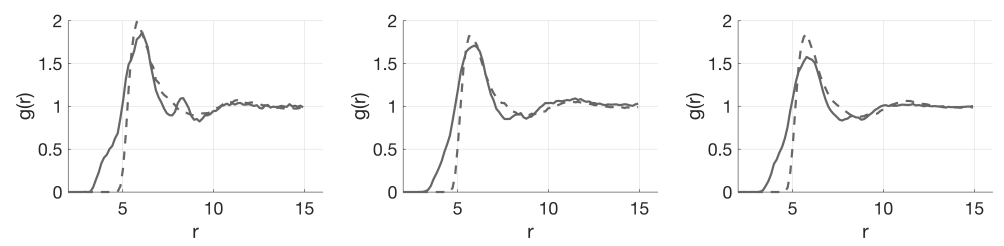

Figure S 3: RDF fit comparing all-atomistic (solid lines) to CG results (dashed lines), for each of the catechol to styrene ratios considered.

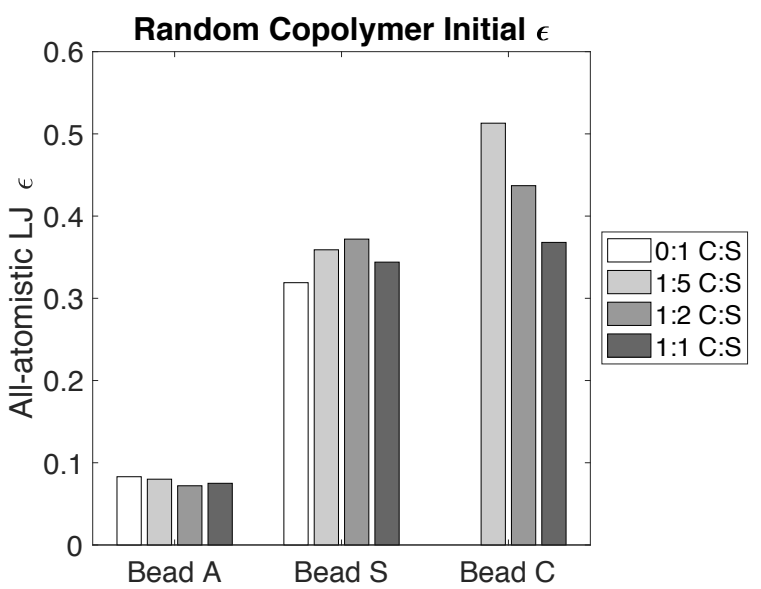

Figure S 4: The initial $\epsilon$ guess generated with the IBI method. 


\section{Stress Strain Response of Poly(catechol-styrene)}
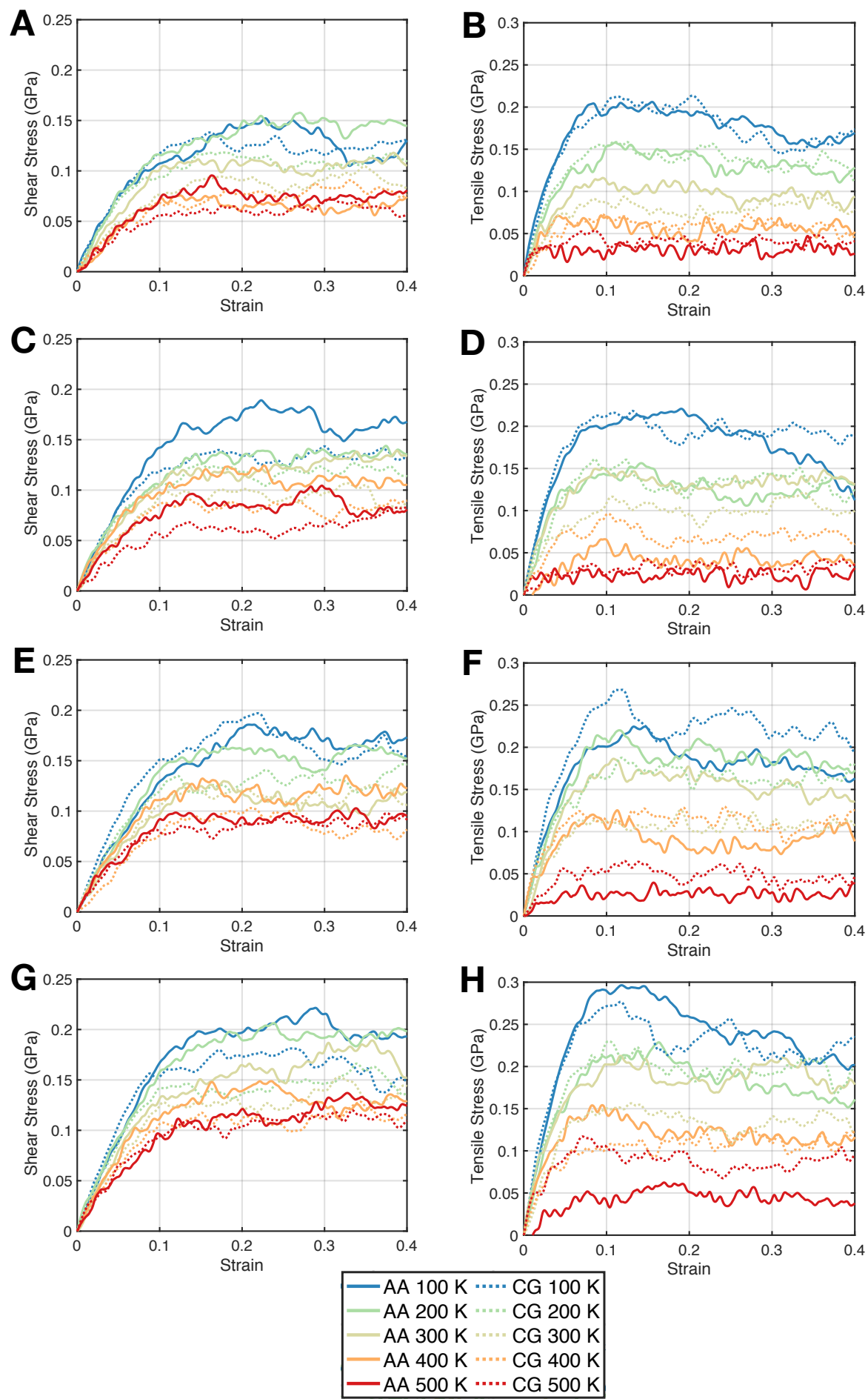

Figure S 5: A-D) The A) shear stress and B) tensile stress of 0:1 C:S, (C-D) 1:5 C:S, (E-F) 1:2 C:S and (G-H) 1:1 C:S copolymer systems, respectively. In all plots, the curves are an average of 3 independent trajectories smoothed by a moving average with a span of 5 data points. All-atomistic results are given by the solid line, while coarse-grained results are given by the dashed line. 